\title{
Face mask use among pedestrians during the COVID-19 pandemic in southwest Iran: An observational study on 10440 people
}

\section{Zahra Rahimi}

Department of Biostatistics and Epidemiology, School of Public Health, Ahvaz Jundishapur University of Medical Sciences

\section{Gholam Abbas Shirali}

Department of Occupational Safety and Health, School of Public Health, Ahvaz Jundishapur University of Medical Sciences

\section{Marzieh Araban}

Department of Health Education and Promotion, School of Public Health, Ahvaz Jundishapur University of Medical Sciences

\section{Mohammad javad Mohammadi}

Department of environmental health engineering, Air pollution and respiratory diseases research center, Ahvaz Jundishapur University of Medical Sciences

\section{Bahman Cheraghian ( $\sim$ cheraghian2000@yahoo.com )}

Hearing Research Center, Department of Biostatistics and Epidemiology, School of Public Health, Ahvaz Jundishapur University of Medical Sciences

\section{Research Article}

Keywords: COVID-19, Face mask, Pedestrian

Posted Date: October 8th, 2020

DOI: https://doi.org/10.21203/rs.3.rs-89832/v1

License: (c) (1) This work is licensed under a Creative Commons Attribution 4.0 International License.

Read Full License 


\section{Abstract}

Background: Many countries have recommended the use of face masks for general population in public places to reduce the risk of COVID-19 transmission. This study aims to estimate the prevalence of face mask usage and investigate about different types of face mask and their distribution among pedestrians in southwest Iran during the Covid-19 pandemic.

Methods: This cross-sectional study was conducted in August 2020 in Ahvaz, southwest Iran. Using a multistage sampling method, a total of 10440 pedestrians selected from 8 urban districts and 92 neighborhoods of the city. The data gathered by observation method. Percentage, mean and standard deviation were used to describe the variables. Chi-square test, fisher exact test and Chi-square for trend used to assess relationship between two categorical variables. We used unconditional logistic regression model to control confounders.

Results: The mean \pm SD age of the observed pedestrians was $32.2 \pm 15.1$ years and $67.9 \%$ of them were male. The overall prevalence of face mask usage was $45.6 \%(95 \% \mathrm{Cl}, 44.6-46.5)$. In general, as the age increased, the prevalence of face mask use significantly increased ( $p$ for trend $<0.001$ ). Women used face masks significantly higher than men $(60.2 \%$ vs. $38.7 \%, p<0.001)$. Among the pedestrians who used the mask, $75.6 \%$ wore facemask correctly. The most common type of facemask used by the pedestrians were surgical(medical) masks (63.8\%). In total, the prevalence of facemask usage was significantly higher during a.m. (49.4\%) compared to p.m. (43.9\%), ( $<<0.001)$. Besides, in our study, $1.7 \%$ and $0.3 \%$ of Pedestrians had worn gloves and shielded respectively. Women used shields and gloves significantly higher than men $(3.6 \%$ vs. $0.7 \%, p<0.001)$. Also, women used shields more than men $(0.5 \%$ vs. $0.3 \%, p$ $=0.036)$.

Conclusion: We concluded that the prevalence rate of face mask use in Ahvaz was fairly low especially in men and younger people. Hence, the observed rates probably cannot protect the community against COVID-19 spread. Therefore, it is important to implement educational programs as well as to establish laws and regulations governing the use of face masks in public places.

\section{Background}

Severe acute respiratory syndrome corona virus 2 (SARS-CoV-2) or corona virus disease 2019 (COVID-19) was initially reported from Wuhan, China on 31 December 2019. The World Health Organization (WHO) declared COVID-19 to be a pandemic on 11 March 2020. It is an ongoing global pandemic now [1]. According to the current evidence, Corona virus is mainly transmitted between individuals via respiratory droplets and contact routes, primarily from person to person during coughing, sneezing, talking[2].

Because there is not any effective treatment or vaccine against COVID-19 yet, personal protective measures including personal protective equipment (PPE) like masks, respirators (i.e. N95 or FFP2), shields and gloves can be used to prevent the infection $[3,4]$. Social distancing and maintaining hand hygiene are the key strategies to prevent COVID-19 transmission (rational) whereas effectiveness of face 
mask usage by the healthy people in the community against COVID-19 is controversial, though increasingly recommended[5,6]. The WHO had not yet recommended mass masking for healthy individuals in the all communities to prevent transmission of COVID-19 in its interim guidance of April 6, 2020, although it suggests the general public to wear a fabric mask in communities with widespread transmission, and especially in settings where physical distancing is difficult to maintain [2]. In the other hand, US Centre for Disease Control (CDC) recommends that people wearing masks in public places to reduce the risk of COVID-19 transmission, when around people outside of their household, especially in settings that social distancing cannot be maintained [4]. However, the use of mask alone is not sufficient to protect a person against COVID-19. It is also necessary to maintain a minimum physical distance from others, frequently washing hands and to avoid touching face (2). Although it is partly unknown the degree that masks protect against droplets/aerosols of respiratory system, [6] but even with a limited protective effect, face masks can reduce the risk of transmission of COVID-19 in the general public [3, 7-9] . They also can presumptively diminish the viral load, resulting to decrease the severity and risk of the death[10].

Masks in point of view filtration efficiency and breathability, can be different. Hence, it is important to use each type of mask in proper setting and situation. Medical masks and respirators are recommended to provide care to suspected or confirmed COVID-19 patients, not in public settings whereas wearing nonmedical (Fabric) masks are recommended in public settings[2, 4].

A national official report announced incidence rate of COVID-19 in Ahvaz is among the highest in Iran [13]. Regarding no data is available on frequency of face mask use in Ahvaz yet, this study aims to estimate the prevalence of face mask usage and investigate about different types of face mask and their distribution among pedestrians in Ahvaz, southwest Iran during the Covid-19 pandemic. This study also aims to assess the acceptance rate of the face mask practice worn by pedestrians. We believe these preliminary findings will help policymakers, managers and health professionals to design and implement their interventional programs.

\section{Methods}

\section{Type of Study}

This population-based cross-sectional study was conducted during 10 days, from 2 to 11 August 2020 in Ahvaz, southwest Iran. A total of 10440 pedestrians selected from 8 urban districts and 92 neighborhoods of the city. Pedestrians mask use behavior was accessed via observation. The data gathering was based on observation of passers-by in street because the observation method usually is more accurate and more valid than the self-reporting approach for assessing behaviors. This study was approved by Ethics Committee of Ahvaz Jundishapur University of Medical Sciences (IR.AJUMS.REC.1399.396).

Inclusion and Exclusion criterialnclusion criterion for this study was all pedestrians $\geq 2$ years old in the city. Exclusion criteria for the study were: 1) fully covered face so that the observer cannot detect whether 
pedestrian wears the mask and, 2) be exposed to the observer for a short time so that it is not possible to record the required information.

\section{Study Setting}

The metropolitan city of Ahvaz is located in the southwest Iran. Ahvaz is the capital of Khuzestan province. It's population according to the 2019 census is 1292752 . Ahvaz has a subtropical hot desert climate with long summers and short winters. The temperature sometimes exceeds $50{ }^{\circ} \mathrm{C}$ during summers and the humidity in sometimes reaches more than $90 \%$.

\section{Data collection}

In this study, The data were gathered by 8 well trained observers. Observation stations were determined according to urban divisions of the city and allocated proportional to the population size, living in each district and neighborhood. These stations were determined from detailed maps of urban divisions and were selected from the crowded passages of each neighborhood. At each station, data of 60 pedestrians were collected including gender, approximate age, use of facemask, gloves and shield, type of facemask, and correct use of facemask. Insufficient coverage of the mouth and nose, wearing facemask upside down or inside-out were defined as "incorrect or unacceptable" use of the mask. Observation was performed during the busy hours of each area from 9.00 to 13.00 and 17.00 to 23.00 .

\section{Sample size and Sampling method}

In order to determine the minimum sample size, we used the formula for estimating a population proportion. For this purpose, $a=0.05, p=0.5, d=0.04$ and a design effect equal to 1.6 were considered. A minimum sample size of 960 estimated for each district. Regarding to the unequal size of the districts and using a proportional to size sampling method, the final sample size needed for this study was estimated 10,440 pedestrians. In total,174 clusters of 60 people from 93 urban neighborhood of Ahvaz were assessed in this study.

We used a Multistage sampling method in this research. At the first stage, each of 8 urban districts was considered as a stratum. Then defined number of clusters were assigned to each neighborhood. Each cluster was consisting of 60 pedestrians. The location of the observation stations was determined by a targeted sampling strategy from the busy passages of each neighborhood. A non-probability convenience sampling method was used for the last stage. In such a way that at each observation station, after deploying the observer, the closest pedestrian to the observer was selected as the first sample and entered to the study. After finished recording the data of the first person, the next closest person to the observer selected as the next sample and this was continued until the total number of selected persons in each cluster reach to 60 .

\section{Statistical analysis}


Descriptive statistical measures including mean, standard deviation and percent used to describe the data. The estimated prevalence rates presented with $95 \%$ confidence interval $(95 \% \mathrm{Cl})$. Chi-square test, fisher exact test and Chi-square for trend used to assess relationship between two categorical variables. We used unconditional logistic regression model to control potential confounders. Odds ratios used to assess strength of the associations. The Statistical significance was declared if the p-value was less than 0.05. The analyses were carried out with SPSS version 22.

\section{Ethics}

The Ethics Committee of Ahvaz Jundishapur University of Medical Sciences (AJUMS.REC.1399.396) confirmed the morality and ethics of the study.

\section{Results}

A total number of 10440 pedestrians were assessed in terms of facemask usage. The mean \pm SD age of the observed pedestrians was $32.2 \pm 15.1$ years. Among the studied individuals, $7072(67.9 \%)$ were male. Demographic characteristic and frequency of personal protective measures among of the assessed pedestrians are shown in Table 1.

Among the observed pedestrians, 4749 people had used facemasks. The overall prevalence of facemask usage was $45.6 \%(95 \% \mathrm{Cl}, 44.6$ - 46.5). The prevalence rates of facemask usage by the assessed factors and their $95 \%$ confidence intervals are presented in Table 2 . The highest prevalence of facemask usage was seen in the age group of 70 years and older, and the lowest was seen in the age group of less than 10 years, $71.7 \%$ and $26.6 \%$ respectively. In general, as the age increased, the prevalence of facemask usage significantly increased too ( $p$ for trend $<0.001$ ). This trend was obviously seen for men but women showed different pattern so that facemask usage in age groups under 10 and, 70 and older were low while the prevalence of facemask usage among the other age groups were higher and almost the same (graph 1). In total, women used facemasks significantly higher than men $(60.2 \%$ vs. $38.7 \%, p$ $<0.001)$.Please insert graph1.

The pedestrians in the eastern area of Ahvaz city worn facemasks significantly more than the western area ( $48.9 \%$ vs. $41.5 \%, p<0.001)$. The prevalence of facemask usage among pedestrians of the eight districts of Ahvaz were highly different, so that the highest prevalence was observed in district two and the lowest was seen in district six, $63.6 \%$ and $20.9 \%$ respectively. The prevalence of facemask usage was even more different among the neighborhoods. It ranged between $1.7 \%$ to $78.3 \%$.

The most common type of facemask used by the observed pedestrians were surgical(medical) masks (63.8\%) and the lowest were the filtered masks including N95 respirators (15.4\%). Older pedestrians wore filtered masks more than younger pedestrians while younger pedestrians used cloth mask more frequently $(p=0.002)$. However, we did not find any significant association between the type of used facemasks and gender ( $p=0.44$ )Among the pedestrians who used the mask, $75.6 \%$ wore facemask correctly, $12.6 \%$ did not cover completely their mouths and noses, $9.9 \%$ wore inside-out and $1.9 \%$ wore 
upside-down. Acceptable facemask practice was significantly higher in women than men (78\% vs.73.9\%; $p=0.017)$ whereas there was no statistically significant difference between the age and correct wearing of facemasks ( $p=0.19$ ). Besides, in our study, $1.7 \%$ and $0.3 \%$ of Pedestrians had worn gloves and shielded respectively. Women used gloves significantly higher than men ( $3.6 \%$ vs. $0.7 \%, p<0.001)$ also wearing gloves was higher in older people $(p=0.033)$. Also, women used shields more than men $(0.5 \%$ vs. $0.3 \%, p=0.036)$ but no significant association was found between use of shields and age $(p=0.34)$ (Table 3).

The observations and data gathering were occurred between 9:00 o'clock to 23.00 o'clock. The lowest prevalence of facemask usage was seen at 13.00 (37.5\%) while the highest was observed at 23.00 (67.9\%). In total, the prevalence of facemask usage was significantly higher during a.m. (49.4\%) compared to p.m. $(43.9 \%),(p<0.001)$. The prevalence rates of facemask usage at different times of day are presented in graph 2.

Please insert graph 2.

Because age and sex could play confounder role in this assessment, unconditional logistic regression model was performed to control effects of these potential confounders. After controlling for age and sex, we observed a significant association between prevalence of facemask usage and time of observations so that the odds of facemask usage during a.m. was 26 percent higher than p.m. (Odds Ratio: OR=1.26; 95\% Cl, 1.16-1.38; $p<0.001)$. The results are presented in Table 4.

\section{Discussion}

At present, COVID-19 has sparked a pandemic and is spreading rapidly in many countries[14]. Because there is no vaccine or effective treatment for this disease, conducting interventions such as use of facemask, social distancing and washing hands are urgently needed to limit the transmission. Despite the WHO primary recommendations against universal masking, emphasis on this strategy is increasing in the world. In Iran, the law on the use of masks in public places, government offices and banks was implemented on June 4.

In this study the prevalence of facemask usage was low (45.6\%). This rate has been inefficient to control the disease hence, Ahvaz was in a critical situation and in the red zone for several months.

In the present study the prevalence of facemask usage was much lower than the rates from Hong Kong study among pedestrians [15], Malaysia study among hospital visitors [16] and Malaysia study on general public at wet markets [17] 94.8\%, 96.9\% and 99.7\% respectively. Similar to our finding observed in Bangkok airport (46\%) [18]. The prevalence rates of face mask use in Lima, Paris, Boston and Atlanta airports (27\%, $4 \%, 3 \%$ and $2 \%$ respectively) [18] were much lower than Ahvaz. The observed differences can be due to demographic and cultural characteristics of the assessed population, different methods of 
data gathering, policy of the governments about mass masking and the risk of COVID19 transmission in the countries.

In our study the highest prevalence of face mask usage was in the age group of 70 years and older (71.7\%). Our result showed the prevalence of face mask usage increased with age. Similar findings were reported among the elderly in Japan (aged 60-69)[19] and Australia (aged 65-74) [20], the percentages face mask usage were $43.6 \%$ and $>60 \%$, respectively. This may be due to the perception of higher risk of morbidity and death due to COVID19 for higher age groups.

Besides, the prevalence of face mask use in women was significantly higher than men $(60.2 \%$ vs. $38.7 \%$, $p<0.001)$. This could be due to the fact that women generally pay more attention to their health status and making healthy behaviors. Conversely, the prevalence rates observed in Malaysia studies showed no difference in both sex[16, 17].

The observed differences in prevalence rates of face mask usage were impressive among the districts and neighborhoods of Ahvaz. This could be mostly due to the differences in socio-economic status. The low socioeconomic level usually leads to low health literacy and public awareness, lack of access to masks, as well as low purchasing power.

The most common type of mask in our study was surgical mask (63.8\%). The same finding reported by Gunasegaram et al. [16, 17] and Tam et al.[15].This can be questionable because the WHO and CDC did not recommend the use of surgical masks in general population [2, 21]. In contrast, they recommended using cloth masks in public setting. This type of masks can be easily manufactured or made at home and reused after washing [22] and it is more affordable than other masks. Besides, we found that the types of face masks were differently used among the age groups. Filtered masks were used higher by older pedestrians while younger people used cloth face masks much higher than the older pedestrians. People in higher age groups usually fill more risk of COVID-19 so they may be use more frequently filtered masks with the purpose of their higher protection.

Our findings showed higher prevalence rates of face mask usage during am hours in relation to pm hours, that it may be due to weather conditions especially the higher temperatures in the afternoon. The similar finding reported by Cheng et al.[5].

Wearing properly a mask is necessary to get the maximum protection against COVID19 [23]. In this study, acceptable rate of using masks among the observed pedestrians was $75.6 \%$. The percentage of acceptable face mask practice in our study was lower than some similar studies. This rates were reported from Malaysia about $95.63 \%$ and $88.75 \%[16,17]$ and from Hong Kong about 87 \% [15] . Besides, we found that the correct practice of face mask use in women was higher than men. This can be due to better following the health protocols by women.

Our study had a number of limitations. Due to use of observation method for the data gathering, we could not assess some important factors like socioeconomic status and the reasons for not wearing masks. 
Besides, we did not ask exact age of the subjects and approximate ages were recorded instead.

Therefore, a non-differential misclassification can be occurred in the age grouping.

This investigation had some major strengths. Using observation method for data gathering in this study can leads to more valid data in comparison to use of questionnaires and self-reporting method.

Furthermore, our large sample size guaranteed sufficient statistical power and precise estimation of the rates so that the calculated confidence intervals are mostly narrow.

\section{Conclusion}

In summary, we found that the overall prevalence rate of face mask usage in Ahvaz was fairly low especially in men. Hence, the observed rates of mask usage probably cannot protect the community against COVID-19 spread. Therefore, it is important to plan and conduct educational programs to promote healthy behaviors in the community, especially for the high risk groups. Besides, to stablish laws and regulations governing the use of face masks in public places is necessary for increasing the rate of mask population coverage.

\section{Abbreviations}

COVID-19: corona virus disease 2019

\section{Declarations}

\section{Ethics approval and consent to participate}

The Ethics Committee of Ahvaz Jundishapur University of Medical Sciences (AJUMS.REC.1399.396) confirmed the morality and ethics of the study.

\section{Consent for publication}

Not applicable.

\section{Availability of data and materials}

Upon request, we can offer onsite access to external researchers to the data analyzed at Ahvaz Jundishapur University of Medical Sciences, Ahvaz, Iran. To do so, Dr. Cheraghian should be contacted.

\section{Competing interests}

The authors declare that they have no competing interests. One of the authors (MA) is a member of the editorial board (Associate Editor) of this journal.

\section{Funding}


Financial support was provided by the Vive-Chancellor for Research at Ahvaz Jundishapur University of Medical Sciences grant number U-99144.

\section{Authors' Contributions}

ZR and BCh were principal investigators of the study and drafted the manuscript. Gh-ASh, MA and M-JM were advisors of the study. BCh performed the statistical analysis. All authors contributed to the design and data analysis and assisted in the preparation of the final version of the manuscript. All authors read and approved the final version of the manuscript.

\section{Acknowledgement}

We appreciate all the observers who helped us to conduct this project.

\section{References}

1. WHO: Naming the coronavirus disease (COVID-19) and the virus that causes it. 2020.

2. World Health O: Advice on the use of masks in the context of COVID-19: interim guidance, 5 June 2020. In. Geneva: World Health Organization; 2020.

3. Keshtkar-Jahromi M, Sulkowski M, Holakouie-Naieni K: Public Masking: An Urgent Need to Revise Global Policies to Protect against COVID-19. The American journal of tropical medicine and hygiene 2020, 102(6):1160-1161.

4. CDC: about-face-coverings. Aug. 6, 2020.

5. Cheng VC, Wong SC, Chuang VW, So SY, Chen JH, Sridhar S, To KK, Chan JF, Hung IF, Ho PL et al: The role of community-wide wearing of face mask for control of coronavirus disease 2019 (COVID-19) epidemic due to SARS-CoV-2. The Journal of infection 2020, 81(1):107-114.

6. Eikenberry SE, Mancuso M, Iboi E, Phan T, Eikenberry K, Kuang Y, Kostelich E, Gumel AB: To mask or not to mask: Modeling the potential for face mask use by the general public to curtail the COVID-19 pandemic. Infectious Disease Modelling 2020, 5:293-308.

7. Worby $\mathrm{CJ}$, Chang H-H: Face mask use in the general population and optimal resource allocation during the COVID-19 pandemic. medRxiv 2020:2020.2004.2004.20052696.

8. Angel N. Desai DMA: Masks and Coronavirus Disease 2019 (COVID-19). JAMA May 26, 2020, 323(20):2103.

9. Chu DK, Akl EA, Duda S, Solo K, Yaacoub S, Schünemann HJ: Physical distancing, face masks, and eye protection to prevent person-to-person transmission of SARS-CoV-2 and COVID-19: a systematic review and meta-analysis. Lancet (London, England) 2020, 395(10242):1973-1987.

10. Střižová Z, Bartůňková J, Smrž D: Can wearing face masks in public affect transmission route and viral load in COVID-19? Central European Journal of Public Health 2020, 28(2):161-162.

11. Fisman DN, Greer AL, Tuite AR: Bidirectional impact of imperfect mask use on reproduction number of COVID-19: A next generation matrix approach. Infectious Disease Modelling 2020, 5:405-408. 
12. Howard JH, A.; Li, Z.; Tufekci, Z.; Zdimal, V.; van der Westhuizen, H.; von Delft, A.; Price, A.; Fridman, L.; Tang, L.; Tang, V.; Watson, G.L.; Bax, C.E.; Shaikh, R.; Questier, F.; Hernandez, D.; Chu, L.F.; Ramirez, C.M.; Rimoin, A.W., 2020040203 (doi: 10.20944/preprints202004.0203.v1). Face Masks Against COVID-19: An Evidence Review. . Preprints 2020.

13. Iran C: Coveid status analysis - 19(In the provinces and cities of Iran). 2020 July 28.

14. (WHO). WHO: Novel coronavirus (SARS-CoV-2) situation reports.

15. Tam VC, Tam SY, Poon WK, Law HKW, Lee SW: A reality check on the use of face masks during the COVID-19 outbreak in Hong Kong. EClinicalMedicine 2020, 22:100356.

16. Gunasekaran GHG, S.S.S.; Gunasekaran, S.S.; Abdul Halim, F.H.B: Prevalence and Acceptance of Face Mask Practice among Individuals Visiting Hospital during COVID-19 Pandemic: An Observational Study. 2020.

17. Gobi Hariyanayagam Gunasekaran SSG, Shargunan Selvanthan Gunasekaran, Nur Syafina Insyirah Binti Zaimi , Nor Amirah Binti Abdul Halim: Prevalence of facemask use among general public when visiting wet market during Covid-19 pandemic: An observational study. 2020.

18. Elachola H, Ebrahim SH, Gozzer E: COVID-19: Facemask use prevalence in international airports in Asia, Europe and the Americas, March 2020. Travel Med Infect Dis 2020, 35:101637-101637.

19. Wada K O-EK, Smith DR Wearing face masks in public during the influenza season may reflect other positive hygiene practices in Japan. BMC Public Health 2012, 12(1):1065-1070.

20. Taylor M RB, Barr M, Agho K, Stevens G, Jorm L. : Public health measures during an anticipated influenza pandemic: factors influencing willingness to comply. Risk Manag Health Care Policy 2009, 2:9-20.

21. CDC: Coronavirus disease 2019 (COVID-19). Recommendation for cloth face covers. 2020.

22. Cheng KK, Lam TH, Leung CC: Wearing face masks in the community during the COVID-19 pandemic: altruism and solidarity. The Lancet.

23. Tirupathi R, Bharathidasan K, Palabindala V, Salim SA, Al-Tawfiq JA: Comprehensive review of mask utility and challenges during the COVID-19 pandemic. Le infezioni in medicina 2020, 28(suppl 1):5763.

\section{Tables}

Table1-Demographic characteristic and frequency of personal protective measures among Pedestrians in Ahvaz. 


\begin{tabular}{|c|c|c|c|}
\hline \multicolumn{2}{|c|}{ variable } & $\mathbf{n}$ & $(\%)$ \\
\hline \multirow[t]{8}{*}{ Age group } & у $0-9$ & 719 & 6.9 \\
\hline & у $10-19$ & 1444 & 13.9 \\
\hline & у $20-29$ & 2456 & 23.6 \\
\hline & у 30-39 & 2778 & 26.7 \\
\hline & y $40-49$ & 1591 & 15.3 \\
\hline & y $50-59$ & 1001 & 9.6 \\
\hline & у $60-69$ & 352 & 3.4 \\
\hline & $\mathrm{y}$ and older 70 & 60 & 0.6 \\
\hline \multirow[t]{2}{*}{ Sex } & Male & 7072 & 67.9 \\
\hline & Female & 3336 & 32.1 \\
\hline \multirow[t]{2}{*}{ Area } & East & 5760 & 55.2 \\
\hline & West & 4680 & 44.8 \\
\hline \multirow[t]{8}{*}{ Urban District } & One & 1680 & 16.1 \\
\hline & Two & 1140 & 10.9 \\
\hline & Three & 1380 & 13.2 \\
\hline & Four & 1140 & 10.9 \\
\hline & Five & 960 & 9.2 \\
\hline & Six & 1440 & 13.8 \\
\hline & Seven & 1200 & 11.5 \\
\hline & Eight & 1500 & 14.4 \\
\hline \multirow[t]{2}{*}{ Face mask use } & Yes & 4749 & 45.6 \\
\hline & No & 5673 & 54.4 \\
\hline \multirow[t]{4}{*}{ Type of face mask } & Surgical mask & 3030 & 63.8 \\
\hline & Cloth mask & 940 & 19.9 \\
\hline & Filtered mask & 731 & 15.4 \\
\hline & Other & 43 & 0.9 \\
\hline \multirow[t]{4}{*}{ How to use a facemask } & correct use & 3586 & 75.6 \\
\hline & Uncovered mouth and/or nose & 598 & 12.6 \\
\hline & inside-out & 470 & 9.9 \\
\hline & upside-down & 90 & 1.9 \\
\hline \multirow[t]{2}{*}{ gloves Use } & Yes & 176 & 1.7 \\
\hline & No & 10246 & 98.3 \\
\hline \multirow[t]{2}{*}{ shield Use } & Yes & 35 & 0.3 \\
\hline & No & 10405 & 99.7 \\
\hline \multirow[t]{2}{*}{ Time } & a.m & 3120 & 29.9 \\
\hline & .p.m & 7320 & 70.1 \\
\hline
\end{tabular}

Table 2-prevalence rates of Face mask usage by sex, Age group, Urban District and Area 


\begin{tabular}{|c|c|c|c|}
\hline & \multirow[t]{2}{*}{ Number of observedpedestrians } & \multicolumn{2}{|r|}{ Face mask usage } \\
\hline & & $\mathrm{n}$ & CI 95\%) prevalence) \\
\hline Overall prevalence & 10422 & 4749 & 45.6 (44.6 to 46.5 ) \\
\hline \multicolumn{4}{|l|}{ Sex } \\
\hline Male & 7063 & 2734 & $38.7(37.6$ to 39.9$)$ \\
\hline Female & 3336 & 2009 & $60.2(58.5$ to 61.9$)$ \\
\hline \multicolumn{4}{|l|}{ Age group } \\
\hline y $0-9$ & 719 & 191 & 26.6 (23.4 to 30.0$)$ \\
\hline у $10-19$ & 1444 & 628 & $43.5(40.9$ to 46.1$)$ \\
\hline у $20-29$ & 2455 & 1161 & $47.3(45.3$ to 49.3$)$ \\
\hline y $30-39$ & 2777 & 1226 & $44.1(42.3$ to 46.0$)$ \\
\hline y $40-49$ & 1587 & 796 & $50.2(47.7$ to 52.6$)$ \\
\hline y $50-59$ & 998 & 480 & $48.1(45.0$ to 51.2$)$ \\
\hline y $60-69$ & 352 & 211 & $59.9(54.6$ to 65.1$)$ \\
\hline and older 70 & 60 & 43 & $71.7(58.6$ to 82.5$)$ \\
\hline \multicolumn{4}{|l|}{ Urban District } \\
\hline One & 1673 & 809 & $48.4(45.9$ to 50.8$)$ \\
\hline Two & 1140 & 725 & $63.6(60.7$ to 66.4$)$ \\
\hline Three & 1377 & 684 & $49.7(47.0$ to 52.3$)$ \\
\hline Four & 1138 & 606 & $53.3(50.3$ to 56.2$)$ \\
\hline Five & 960 & 307 & $32.0(29.0$ to 35.0$)$ \\
\hline Six & 1439 & 301 & $20.9(18.1$ to 22.2$)$ \\
\hline Seven & 1197 & 430 & $35.9(33.2$ to38.7) \\
\hline Eight & 1498 & 887 & $59.2(56.7$ to 61.7$)$ \\
\hline \multicolumn{4}{|l|}{ Area } \\
\hline East & 5745 & 2810 & (to 50.247 .6 ) 48.9 \\
\hline West & 4677 & 1939 & (to 42.940 .0 ) 41.5 \\
\hline
\end{tabular}

Table 3 - Association between personal protective measures and sex among Pedestrians in Ahvaz. 


\begin{tabular}{|c|c|c|c|c|}
\hline Variables & $\begin{array}{l}\text { Male } \\
\text { (\%) n }\end{array}$ & $\begin{array}{c}\text { Female } \\
\text { (\%)n }\end{array}$ & $\begin{array}{l}\text { Total } \\
\text { (\%)n }\end{array}$ & $*$ p-value \\
\hline Type of face mask & & & & \multirow{6}{*}{0.44} \\
\hline Surgical mask & $(63.7) 1741$ & $(64.2) 1289$ & (63.8)3030 & \\
\hline Cloth mask & $(19.7) 540$ & (19.9) 400 & (19.8)940 & \\
\hline Filtered mask & (16.3)446 & $(14.2) 285$ & $(15.4) 731$ & \\
\hline Other & $(0.3) 8$ & $(1.7) 35$ & $(0.9) 43$ & \\
\hline Total & $(100) 2735$ & $(100) 2009$ & $(100) 4744$ & \\
\hline \multicolumn{4}{|l|}{ How to use facemask } & \multirow{6}{*}{0.017} \\
\hline correct use & (73.9) 2020 & (78.0)1566 & (75.6)3586 & \\
\hline Uncovered mouth and/or nose & (14.3)391 & $(10.3) 207$ & (12.6)598 & \\
\hline inside-out & (9.7) 267 & $(10.1) 203$ & $(9.9) 470$ & \\
\hline upside-down & $(2.1) 58$ & $(1.7) 32$ & (1.9)90 & \\
\hline Total & $(100) 2735$ & $(100) 2009$ & $(100) 4744$ & \\
\hline \multicolumn{4}{|l|}{ Gloves use } & \multirow{4}{*}{$0.001>$} \\
\hline Yes & $(0.7) 48$ & (3.6)128 & (1.7)176 & \\
\hline No & (99.3) 6778 & $(96.4) 3460$ & (98.3)10238 & \\
\hline Total & $(100) 6826$ & $(100) 3588$ & (100) 10414 & \\
\hline \multicolumn{4}{|l|}{ shield use } & \multirow{4}{*}{0.036} \\
\hline Yes & (0.3)18 & $(0.5) 17$ & $(0.3) 35$ & \\
\hline No & (99.7) 7054 & (99.5)3319 & (99.7)10373 & \\
\hline Total & (100) 7072 & $(100) 3336$ & (100) 10408 & \\
\hline
\end{tabular}

* The P values used in this table were obtained by chi-square test

Table 4- The crude and adjusted Odds Ratios for effects of time on face mask prevalence using multiple logistic regression model. 


\begin{tabular}{|c|c|c|c|c|}
\hline Variables & Crude ORs & P-value & Adjusted ORs & P-value \\
\hline \multicolumn{5}{|l|}{ Age group } \\
\hline у $0-9$ & $(0.26-0.08) 0.14$ & \multirow[t]{8}{*}{$0.001>$} & $(0.2-0.06) 0.1$ & \multirow[t]{8}{*}{$0.001>$} \\
\hline у $10-19$ & $(0.32-0.19) 0.24$ & & $(0.27-0.15) 0.2$ & \\
\hline у $20-29$ & $(0.48-0.32) 0.39$ & & $(0.43-0.28) 0.35$ & \\
\hline у $30-39$ & $(0.44-0.30) 0.36$ & & $(0.46-0.28) 0.34$ & \\
\hline y $40-49$ & $(0.55-0.38) 0.46$ & & $(0.51-0.35) 0.42$ & \\
\hline y $50-59$ & $(0.48-0.34) 0.40$ & & $(0.46-0.32) 0.38$ & \\
\hline у $60-69$ & $(0.57-0.39) 0.47$ & & $(0.55-0.37) 0.45$ & \\
\hline y and older 70 & 1 & & 1 & \\
\hline \multicolumn{5}{|l|}{ Sex } \\
\hline Male & 1 & \multirow[t]{2}{*}{$0.001>$} & 1 & \multirow[t]{2}{*}{$0.001>$} \\
\hline Female & $(0.45-0.38) 0.42$ & & $(0.43-0.36) 0.39$ & \\
\hline \multicolumn{5}{|l|}{ Time } \\
\hline .a.m & 1 & \multirow[t]{2}{*}{$0.001>$} & 1 & \multirow[t]{2}{*}{$0.001>$} \\
\hline .p.m & $(1.35-1.14) 1.24$ & & $(1.38-1.16) 1.26$ & \\
\hline
\end{tabular}

\section{Figures}

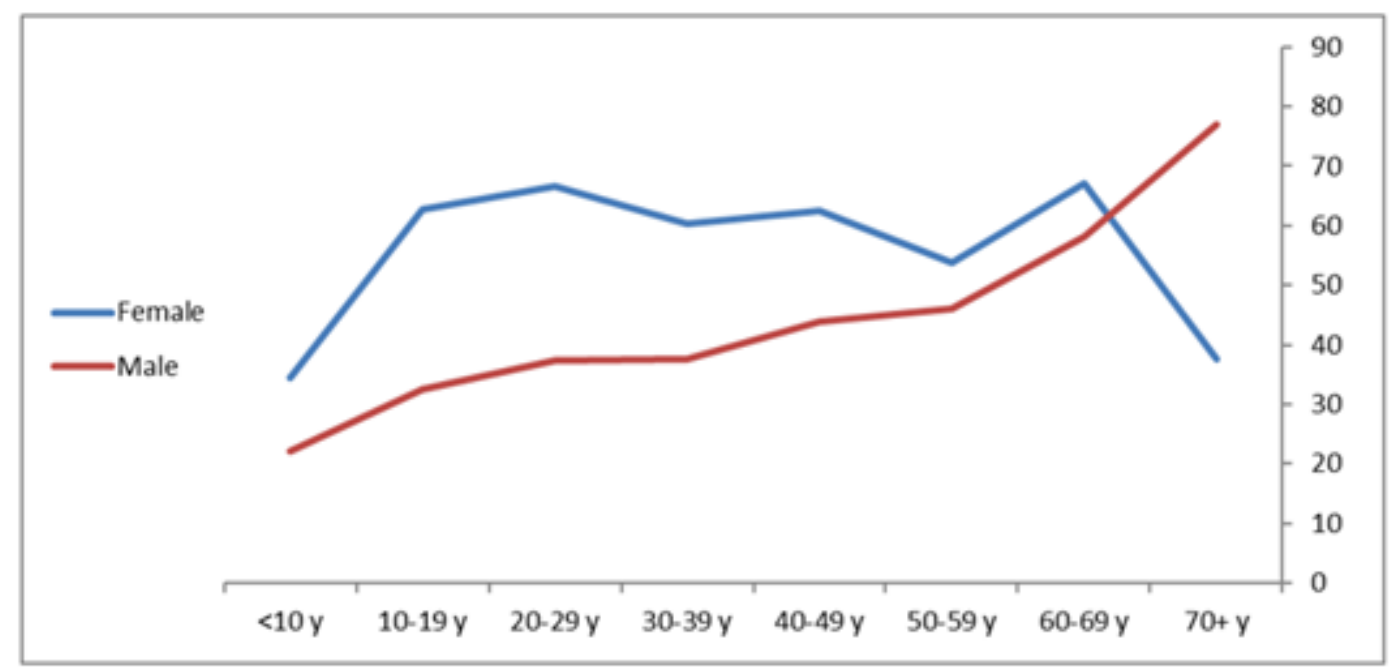

Figure 1

Comparison of age trends of mask usage by gender 


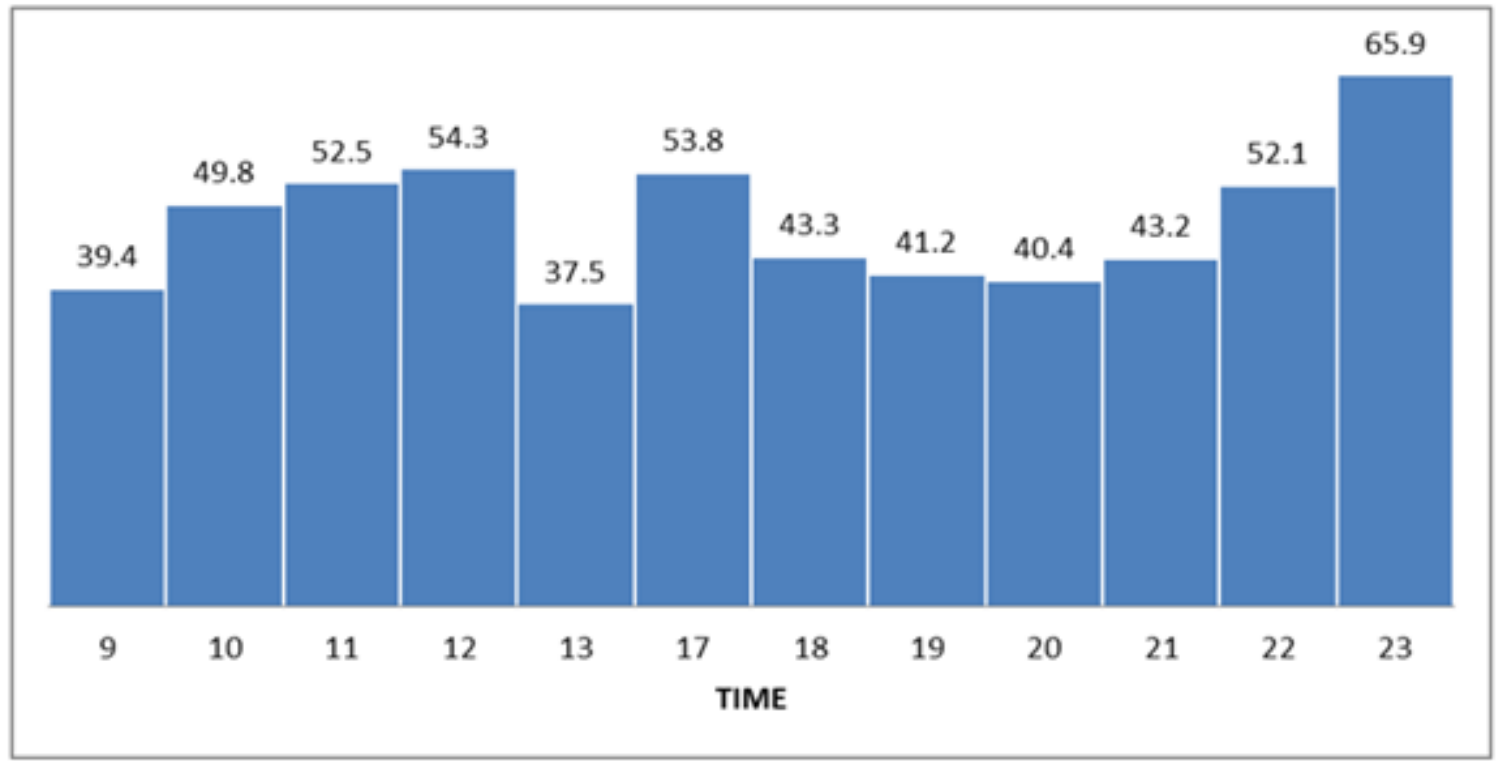

Figure 2

The prevalence rates of facemask usage at different times of day 